\title{
Identification of a stem-like cell population by exposing metastatic breast cancer cell lines to repetitive cycles of hypoxia and reoxygenation
}

Elizabeth Louie', Sara Nik', Juei-suei Chen ${ }^{1}$, Marlies Schmidt ${ }^{1}$, Bo Song ${ }^{2}$, Christine Pacson ${ }^{1}$, Xiu Fang Chen ${ }^{1}$, Seonhye Park', Jingfang Ju², Emily I Chen ${ }^{1 *}$

\begin{abstract}
Introduction: The irregular vasculature of solid tumors creates hypoxic regions, which are characterized by cyclic periods of hypoxia and reoxygenation. Accumulated evidence suggests that chronic and repetitive exposure to hypoxia and reoxygenation seem to provide an advantage to tumor growth. Although the development of hypoxia tolerance in tumors predicts poor prognosis, mechanisms contributing to hypoxia tolerance remain to be elucidated. Recent studies have described a subpopulation of cancer stem cells (CSC) within tumors, which have stem-like properties such as self-renewal and the ability to differentiate into multiple cell types. The cancer stem cell theory suggests CSCs persist in tumors as a distinct population and cause relapse and metastasis by giving rise to new tumors. Since hypoxia is considered to be one of the critical niche factors to promote invasive growth of tumors, we hypothesize that repetitive cycles of hypoxia/reoxygenation also play a role in the enrichment of breast CSCS.

Methods: Two metastatic human breast cancer cell lines (MDA-MB 231 and BCM2) were used to optimize the conditions of hypoxia and reoxygenation cycles. The percentage of CSCs in the cycling hypoxia selected subpopulation was analyzed based on the CD44, CD24, ESA, and E-cadherin expression by three-color flow cytometry. Colony formation assays were used to assess the ability of this subpopulation to self-renew. Limiting dilution assays were performed to evaluate the tumor-initiating and metastatic ability of this subpopulation. Induction of EMT was examined by the expression of EMT-associated markers and EMT-associated microRNAs.

Results: Using an optimized hypoxia and reoxygenation regimen, we identified a novel cycling hypoxia-selected subpopulation from human breast cancer cell lines and demonstrated that a stem-like breast cancer cell subpopulation could be expanded through repetitive hypoxia/reoxygenation cycles without genetic manipulation. We also found that cells derived from this novel subpopulation form colonies readily, are highly tumorigenic in immune-deficient mice, and exhibit both stem-like and EMT phenotypes.
\end{abstract}

Conclusions: These results provide the validity to the newly developed hypoxia/reoxygenation culture system for examining the regulation of CSCS in breast cancer cell lines by niche factors in the tumor microenvironment and developing differential targeting strategies to eradicate breast CSCs.

\section{Introduction}

Recent studies have described a subpopulation of cancer cells within tumors termed 'cancer stem cells' (CSCs), which have stem-like properties such as self-renewal and

\footnotetext{
* Correspondence: emily@pharm.stonybrook.edu

'Department of Pharmacological Sciences, Stony Brook University, BST-125, Stony Brook, NY 11794, USA

Full list of author information is available at the end of the article
}

the ability to differentiate into multiple cancer cell types [1-7]. The CSC theory suggests that such CSCs persist in tumors as a distinct population and cause relapse and metastasis by giving rise to new tumors [8-10]. Although CSCs make up only a small fraction of a tumor, they possess the unique capability to regenerate a tumor whereas most tumor cells lack this regenerative capability $[11,12]$. By means of a non-obese diabetic/severe combined

\section{Ciomed Central}

(c) 2010 Louie et al.; licensee BioMed Central Ltd. This is an open access article distributed under the terms of the Creative Commons Attribution License (http://creativecommons.org/licenses/by/2.0), which permits unrestricted use, distribution, and reproduction in any medium, provided the original work is properly cited. 
immunodeficiency disease (NOD/SCID) xenotransplant assay in combination with specific cell surface markers $\left(\mathrm{CD} 44^{+} \mathrm{CD} 24^{-/ \text {low }}\right), \mathrm{CSCs}$ were enriched from metastatic and primary breast tumors and were shown to have the ability to reestablish tumor heterogeneity after transplantation [1]. Since then, additional CSC markers have been proposed and studied to isolate putative tumor stem cell populations. However, as demonstrated by a recent report from Stuelten and colleagues [13], the complexity of CSC markers continues to pose challenges for identifying and isolating the putative tumor stem cell populations by the cell-sorting approach. In addition to initiating tumors, CSCs are thought to be capable of initiating metastasis. The link between CSCs and metastasis has been suggested by several studies. First, breast CSCs were shown to invade through Matrigel, a basement membrane matrix used routinely as an indicator of metastatic potential of cancer cells [14]. Second, a recent study demonstrated that there is a link between epithelial-mesenchymal transition (EMT) and breast CSCs [15]. Furthermore, the prevalence of $\mathrm{CD} 44^{+} \mathrm{CD} 24^{-}$cells in breast cancer patients indicates a link between high numbers of stem-like cancer cells and metastasis [16]. However, only a few studies have directly tested the metastatic capability of putative CSCs in vivo. Collective evidence from a few studies that directly tested the in vivo metastasis using sorted CSCs suggests that the CSC phenotype alone may exhibit invasive property in vitro but is inadequate to determine or predict in vivo metastasis. For example, in pancreatic cancer, CSCs $\left(\mathrm{CD} 133^{+}\right.$cells $)$were not able to metastasize when injected orthotopically at low numbers [17]. In mammary carcinomas, $\mathrm{CD} 44^{+} \mathrm{CD} 24^{\text {low }}$ cells were invasive in vitro but the phenotype was not sufficient for metastasis when cells were injected intracardiacally in vivo [14]. Therefore, we set out to investigate alternative mechanisms that could enrich for breast CSCs with tumor-initiating and metastatic capabilities.

To identify factors that distinguish the malignant subpopulation within breast tumors, we began to explore environmental influences known to associate with aggressively metastatic breast tumors. It has been postulated that hypoxia contributes directly to the development of more aggressive cancers by exerting selective pressure on the tumor cell population to favor cells that can survive decreased $\mathrm{O}_{2}$ and nutrients [18-20]. During tumor development, rapid expansion of cancer cells creates a hypoxic microenvironment that is followed by periods of reoxygenation to promote tumor progression. These two aspects of tumor progression (hypoxia and reoxygenation) cooperate to provide growth advantages essential for the progressive development of aggressive tumors [21]. Although extensive efforts have been devoted to understanding the effect of hypoxia on tumor progression, two areas of tumor biology remain unclear. What is the effect of fluctuating oxygen tension on tumor progression? How does hypoxia drive an irreversible phenotype without genetic manipulation? It is known that both hypoxia and consecutive hypoxia/reoxygenation can exert a variety of effects on tumor cell biology, including activation of pro-survival signal transduction pathways, aberrant genetic and epigenetic alterations, and increased tumor angiogenesis. In some studies, hypoxia/reoxygenation was shown to drive expression of proteins associated with poor prognosis [22]. Furthermore, susceptibility of genomic instability can vary after acute or chronic exposure to hypoxia followed by reoxygenation [23]. Therefore, we hypothesize that hypoxia/ reoxygenation cycles may provide the driving force to select for a highly metastatic breast CSC subpopulation.

To study the effect of hypoxia/reoxygenation cycles on breast cancer, we exposed two metastatic human breast cancer cell lines (MDA-MB 231 and BCM2) to cycles of chronic hypoxia and nutrient deprivation. After one cycle of hypoxia and reoxygenation, we observed a small cell population that survived hypoxia as spherical clusters under hypoxic conditions and that resumed proliferation after reoxygenation. We then isolated and exposed this novel subpopulation to additional cycles of hypoxia/reoxygenation and established a distinct subpopulation of cells from these two breast cancer cell lines. As expected, this novel subpopulation showed increasing viability under hypoxia and the ability to proliferate as either an adherent monolayer or substrate-independent tumor spheres. Interestingly, an increased fraction of the cell population was found to express $\mathrm{CD}_{4} 4^{+} / \mathrm{CD}_{24} / \mathrm{ESA}^{+}$cell surface markers. However, this novel subpopulation was distinguished by being highly tumorigenic and metastatic and showed upregulation of EMT markers. These findings strongly suggest that we have succeeded in isolating a unique metastatic CSC population by exposing breast cancer cells to repetitive cycles of hypoxia and reoxygenation.

\section{Materials and methods}

\section{Cell lines and tissue culture}

MDA-MB 231 was purchased from American Type Culture Collection (Manassas, VA, USA); BCM2 cell line was obtained from Brunhilde Felding-Habermann (Scripps Research Institute, La Jolla, CA, USA). MDAMB 231 and BCM2 cell lines were cultured in minimum essential medium (MEM) (Invitrogen Corporation, Carlsbad, CA, USA) supplemented with $10 \%$ fetal bovine serum (HyClone, Logan, UT, USA; Thermo Fisher Scientific Inc., Waltham, MA, USA), 2 mM L-glutamine, $1 \mathrm{mM}$ sodium pyruvate, $1 \mathrm{mM}$ non-essential amino acids, and $1 \%$ vitamin (HyClone). All cell lines were grown at $37^{\circ} \mathrm{C}$ and in $5 \%$ carbon dioxide. 


\section{Flow cytometry}

Non-confluent cultures were trypsinized into single-cell suspension, counted, washed with phosphate-buffered saline (PBS), and fixed with 10\% paraformaldehyde. Cells were stained with antibodies specific for human cell surface markers: CD326/ESA-FITC, CD24-PE, and CD44PE-Cy7 (BD Pharmingen, San Jose, CA, USA). E-cadherin antibody was purchased from Cell Signaling Technology, Inc. (Danvers, MA, USA). A total of $2 \times 10^{5}$ cells were incubated with antibodies for 30 minutes on ice. Unbound antibody was washed, and cells were analyzed on a Guava EasyCyte Plus Flow Cytometer (Millipore Corporation, Billerica, MA, USA). The Student $t$ test was used to calculate the significance of increased CD44 ${ }^{+} / \mathrm{CD} 24^{-} / \mathrm{ESA}^{+}$and E-cad $/ \mathrm{CD} 44^{+} / \mathrm{CD} 24^{-}$populations in the cycling hypoxia-selected subpopulations.

\section{Viability and cell proliferation assay}

Cells were collected from either the media (floating subpopulation) or the adherent subpopulation after each hypoxic cycle and dissociated into single-cell suspension by trypsin/EDTA (trypsin/ethylenediaminetetraacetic acid). Guava ViaCount Reagent (Millipore Corporation) was used to determine the viability and cell numbers after each hypoxic cycle. For cell proliferation assay, $5 \times 10^{4}$ cells were seeded in triplicate wells per cell line per time point in 12-well tissue culture plates. Cells were detached (adherent culture) or dissociated (spherical culture) by trypsin/EDTA and resuspended in PBS for cell counting using the ViaCount assay. In accordance with the manufacturer's instructions, an appropriate volume of the ViaCount Reagent was mixed with $50 \mu \mathrm{L}$ of cell suspension in PBS. After 5 minutes of incubation at room temperature in the dark, ViaCount/cell mixture was loaded into a 96-well microtiter plate and read by the Guava Flow Cytometer. Both live and dead cells were detected and displayed in dot plots. The Guava ViaCount software carried out calculation of viability and cell numbers for each sample automatically.

\section{Colony-forming assays}

For the colony formation assay, cells were trypsinized to generate single-cell suspensions and counted by a hemocytometer. Single-cell suspensions (500 cells per well) were plated on 96-well plates with an ultralow attachment surface. Three wells were seeded for each cell line, and triplicate experiments were performed per cell line $(n=3)$. The EVOS microscope (Advanced Microscopy Group, Bothell, WA, USA) was used to count tumor spheres and take images of each well on days 1, 3, 5, and 9. Immediately after the cells were seeded, each well was checked under the microscope to verify the sparseness of each spherical culture, and only wells containing singlecell suspension with no cell cluster were chosen for tumor-sphere counting after 9 days. Colonies of at least $60 \mu \mathrm{m}$ in diameter (determined by using an eyepiece graticule with crossed scales) were counted on day 9 after plating. Colony-forming efficiency (CFE) was calculated by dividing the number of colonies $(>60 \mu \mathrm{m})$ formed by the original number of single cells seeded and is expressed as a percentage.

\section{Animals and surgery}

All animal procedures were performed in accordance with an approved protocol by the Stony Brook University Institutional Animal Care and Use Committee. NOD/SCID mice were purchased from the Jackson Laboratory (Bar Harbor, ME, USA). Four- to six-week-old female mice were used for tumor injections. Human breast cancer cells were suspended in sterile Hank's buffered salt solution (HBSS) and injected into the third thoracic mammary gland. Tumor formation was assessed by palpation at least once a week. A caliper was used to measure the length and width of tumors at least once a week. A standard formula for calculating tumor volume (in cubic millimeters) was used: length $\times(\text { width })^{2} / 2$. Duplicate experiments were performed for each cell number.

\section{Quantification of lung metastasis}

Five to six weeks after the resection of primary tumors from tumor-bearing NOD/SCID mice, lungs were harvested and fixed in the Bouin's fixative solution overnight. Nodules on the surface of lungs were visualized under the dissecting microscope, and a USB digital camera (Leica Microsystems, Bannockburn, IL, USA) from the microscope was used to take gross images of each lung. To quantify the tumor burden, each image was first annotated with the National Institutes of Health ImageJ software to identify measurable nodules on the surface of the lung. The length and width of each nodule were measured with pixels and then converted to millimeters to calculate the tumor volume. A standard formula for calculating tumor volume (cubic millimeters) was used: length $\times(\text { width })^{2} / 2$. Metastatic tumor burden of each animal was calculated by combining tumor volumes from four lobes of lungs. Average tumor burden and standard deviations were derived from at least four animals per group.

\section{Western blot analysis}

Subcellular fractionation of cell lysates was prepared using the ProteoExtract Subcellular Proteome Extraction Kit (Calbiochem-EMD Biosciences, San Diego, CA, USA), and protein concentrations were determined by EZQ Protein Quantification Kit (Invitrogen Corporation). Proteins from nuclear or cytoplasmic fractions $(40 \mu \mathrm{g})$ were resolved by $4 \%$ to $20 \%$ SDS-PAGE and transferred onto nitrocellulose membranes for immunoblotting. Immunoblotting assays were carried out by standard 
procedures using Snail (Cell Signaling Technology, Inc.) and vimentin antibodies (Novus Biologicals, Littleton, CO, USA). Anti- $\beta$-actin antibody (Sigma-Aldrich, St. Louis, MO, USA) was used to confirm equal protein loading of cytoplasmic fractions. Anti-histone H3 antibody (Millipore Corporation) was used to confirm equal protein loading of nuclear fractions. Secondary antibodies conjugated with either AF680 (Invitrogen Corporation) or CW800 (LI-COR Biosciences, Lincoln, NE, USA) were used to visualize protein bands using the Odyssey Infrared Imager (LI-COR Biosciences).

\section{Analysis of the mRNA and microRNA expression by quantitative reverse transcription-polymerase chain reaction assay}

Total RNA was isolated from each cell line using an RNA Extraction Kit (Qiagen Inc., Valencia, CA, USA) in accordance with the manufacturer's instructions. One point two micrograms of total RNA from each cell line was reversetranscribed using random primers and the High-Capacity cDNA Synthesis Kit (Applied Biosystems, Foster City, CA, USA). The resulting cDNAs were mixed with the SYBR PCR [polymerase chain reaction] master mix (Applied Biosystems) and run on the StepOnePlus Applied Biosystems Real-time PCR machine. One cycle of denaturing step $\left(10\right.$ minutes at $\left.95^{\circ} \mathrm{C}\right)$ was applied, followed by 35 cycles of amplification $\left(15\right.$ seconds at $95^{\circ} \mathrm{C}$ and 1 minute at $\left.58^{\circ} \mathrm{C}\right)$, with fluorescence measured during the extension. Primers used to amplify the human Snail gene have the following sequences: 5'-CCTCCCTGTCAGATGAGGAC-3' (forward) and 5'-CCAGGCTGAGGTATTCCTG-3' (reverse). Primers used to amplify the human Slug gene have the following sequences: 5'-GGGGAGAAGCCTTTTTCTTG-3' (forward) and 5'-TCCTCATGTTTGTGCAGGAG-3' (reverse). Primers used to amplify the human Twist gene have the following sequences: 5'-GGAGTCCGCAGTCTTACGAG-3' (forward) and 5'-TCTGGAGGACCTGGTAGAGG-3' (reverse). The relative quantification (RQ) value reflects the fold changes of mRNA expression in each cell line compared with the parental cell lines. RQ was calculated using the comparative $C_{\mathrm{T}}\left(\Delta \Delta C_{\mathrm{T}}\right)$ method and StepOne software version 2.0.1 (Applied Biosystems) and normalized by the expression of the housekeeping gene, GAPDH (glyceraldehyde-3-phosphate dehydrogenase). Three independent experiments were performed to derive average RQ and standard deviations $(n=3)$.

For microRNA (miRNA) analysis, total RNAs, including miRNAs, were isolated from the cell lines using TRIzol reagent (Invitrogen Corporation) in accordance with the manufacturer's instructions. Ten nanograms of total RNA from each cell line was converted to cDNA using the High-Capacity cDNA synthesis kit (Applied Biosystems). The miRNA sequence-specific reverse transcription-PCR (RT-PCR) primers for miR-200c, miR-205, and an endogenous control RNU6B were purchased from Ambion (Austin, TX, USA). Real-time quantitative RTPCR (qRT-PCR) analysis was performed using the 7500 Real-Time PCR System from Applied Biosystems. The TaqMan master mix was added to the cDNA and primer mix to amplify and quantify target miRNAs (No AmpErase UNG; Applied Biosystems). The following PCR cycle was used for miRNA amplifications: $95^{\circ} \mathrm{C}$ for 10 minutes and 40 cycles of $95^{\circ} \mathrm{C}$ for 15 seconds and $60^{\circ} \mathrm{C}$ for 60 seconds. The RQ value reflects the fold changes of miRNA expression in each cell line compared with the parental cell lines. RQ was calculated using the comparative $C_{\mathrm{T}}$ $\left(\Delta \Delta C_{\mathrm{T}}\right)$ method and StepOne software version 2.0.1 (Applied Biosystems) and normalized by the expression of the internal control RNU6B. Three independent experiments were performed to derive average RQ and standard deviations $(n=3)$.

\section{Results}

\section{Establishing optimized conditions for hypoxia and reoxygenation selection}

To study the effect of repetitive hypoxia/reoxygenation on breast cancer cells, we optimized conditions of hypoxia and reoxygenation with regard to the number of cycles, exposure time, cell numbers, and other parameters. We used two metastatic breast cancer cell lines, MDA-MB 231 and BCM2 [24], to ensure that our current protocol was not cell line-specific. To establish efficient and reproducible hypoxia/reoxygenation conditions, we used the ProOxC system (BioSpherix, Lacona, NY, USA), which allows precise oxygen control over an extended time period via an oxygen sensor and automatic feedback mechanisms to maintain a consistently low oxygen environment. The optimized procedure included exposing these breast cancer cell lines $\left(1 \times 10^{7}\right.$ cells in a T125 tissue culture flask, approximately $60 \%$ confluency) to hypoxia $\left(1 \% \mathrm{O}_{2}\right)$ and nutrient deprivation for 7 days, mimicking the avascular microenvironment, and reoxygenating surviving cells for 1 to 3 weeks depending on the viability of surviving cells (Figure 1). The same growth media used to maintain monolayer cultures (see Materials and methods) were used to prepare the cells and maintain the adherent and nonadherent cells in culture. After each hypoxic cycle, $10 \%$ of the adherent culture became non-adherent (floating cell population). Using this protocol, we consistently observed novel surviving populations that were nonadherent and that demonstrated a propensity to form spherical clusters under hypoxic conditions. However, unlike the adherent hypoxia-resistant cells, only $10 \%$ of the total non-adherent cells were viable after the first round of hypoxic cycle (F1). After reoxygenating and growing F1 cells as spherical cultures, we exposed the same amount of F1 cells to a second hypoxic cycle and 


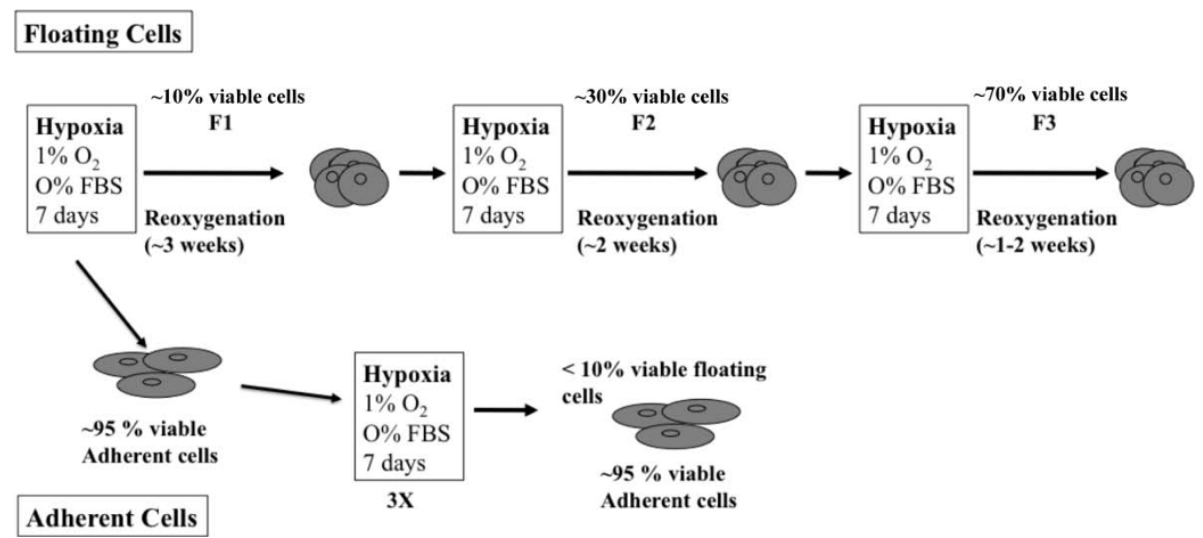

Figure 1 An illustration of the hypoxia and reoxygenation regimen. Conditions for hypoxia/reoxygenation cycles were optimized using two human metastatic breast cancer cell lines (MDA-MB 231 and BCM2). The viability of non-adherent cells is listed after each hypoxic cycle. FBS, fetal bovine serum.

found an increase in viability (30\%) (F2). After three rounds of hypoxia and oxygenation, we found that the viability of the non-adherent cells increased to $70 \%$ (F3). Additional rounds of hypoxia did not increase the percentage of survival significantly. In addition to finding increased hypoxia viability, we found distinct characteristics in this novel subpopulation. For comparison purposes, we exposed the adherent hypoxia-resistant cells to two additional rounds of hypoxia/reoxygenation selection and generated the hypoxia-exposed adherent cell population (A3).

The newly isolated cycling hypoxia-selected breast cancer subpopulation has increased tumor-initiating capability

Since hypoxia has been implicated in the promoting of aggressive tumors, we first examined the tumor-initiating ability of the parental and newly isolated cycling hypoxia-selected subpopulation in immune-deficient mice. We orthotopically injected either parent MDAMB 231 and BCM2 or the cycling hypoxia-selected subpopulations (MDA-MB $231 \mathrm{~F} 3$ and BCM2 F3) into NOD/SCID mice as a limiting dilution assay from $5 \times$ $10^{5}$ to $5 \times 10^{2}$ cells per mammary gland. Although there was no noticeable difference in the frequency of tumor formation between these two cell populations (MDAMB 231 and MDA-MB 231 F3) when $5 \times 10^{5}$ cells were injected, a dramatic difference in tumor initiation and growth was observed when 10-fold, 100-fold, and 1,000fold fewer cells were injected in NOD/SCID mice (Figure 2a). With as few as 500 cells, MDA-MB 231 F3 and BCM2 F3 cells could form tumors in NOD/SCID mice, whereas both parent cell lines were not able to do so at the same dilution (Table 1 and Figure $2 \mathrm{~b}, \mathrm{c}$ ). Furthermore, tumors progressed rapidly in mice injected with lower numbers of MDA-MB 231 F3 cells and BCM2 F3 cells $\left(5 \times 10^{4}\right.$ cells $)$ than equivalent numbers of MDA-MB 231 cells (Figure 2a-c), indicating that MDA-MB 231 F3 cells formed more aggressive tumors. We also injected 500 hypoxia-exposed adherent cells (MDA-MB 231 A3 and BCM2 A3) in the mammary fat pad of female NOD/SCID mice. None of the mice injected with 500 MDA-MB 231 A3 or BCM2 A3 cells developed mammary tumors by 90 days (MDA-MB 231 A3) or 98 days (BCM2 A3) (Table 1). We conclude that the newly isolated cycling hypoxia-selected nonadherent subpopulation is highly tumorigenic compared with the hypoxia-exposed adherent and parental cell lines.

The newly isolated cycling hypoxia-selected breast cancer subpopulation comprises putative breast cancer stem cell population $\left(\mathrm{CD}^{+} 4^{+} / \mathrm{CD}^{-} 4^{-} / \mathrm{ESA}^{+}\right)$

Evidence of stem-like cancer cells has been established in various types of cancer, including breast cancer $[1,3,4,7,8,12,25]$. This small subpopulation has been shown to be highly tumorigenic and exhibits some stem cell characteristics such as self-renewal and the ability to form tumor spheres $[12,26]$. Since the newly isolated cycling hypoxia-selected subpopulation is highly tumorigenic, we hypothesized that this subpopulation is enriched with stem-like breast cancer cells. Using the three-color flow cytometry analysis, we found that the cycling hypoxia-selected subpopulation displayed an increased proportion of cells with the surface marker expression of $\mathrm{CD} 44^{+} / \mathrm{CD} 24^{-} / \mathrm{ESA}^{+}$, which has been reported as putative breast CSCs. The percentage of the $\mathrm{CD} 44^{+} / \mathrm{CD} 4^{-} / \mathrm{ESA}^{+}$cell population was significantly increased in the cycling hypoxia-selected subpopulation in comparison with the parental breast cancer cell lines (3-fold increase in MDA-MB 231 F3 cells, Figure 3a,c; 13-fold increase in BCM2 F3, Figure 3b,c; Figure S1 in Additional file 1). Since it has been reported that hypoxia exposure alone can increase the stem-like cell 


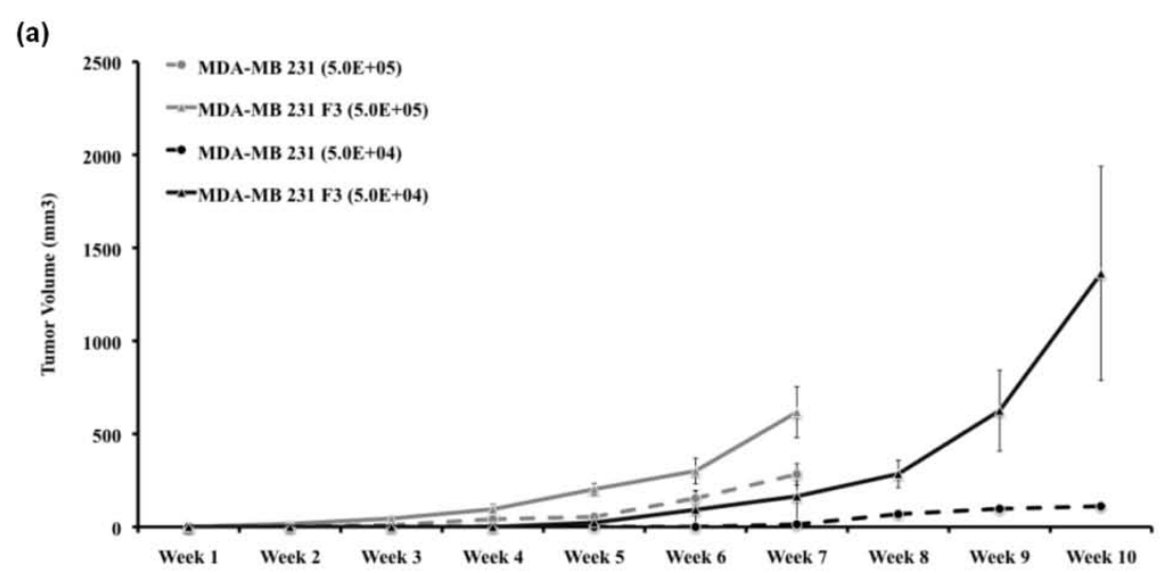

(b)

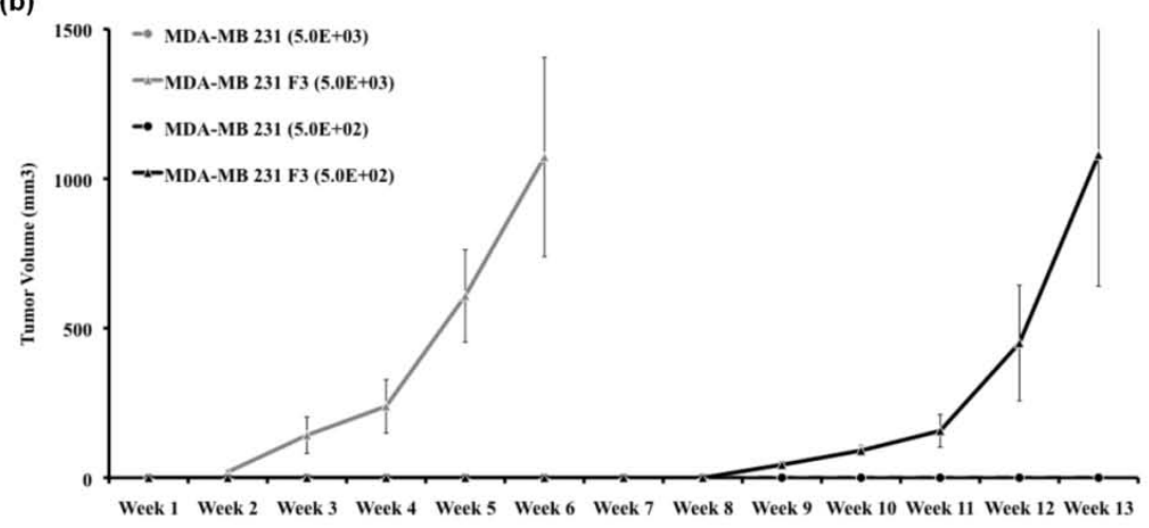

(c)

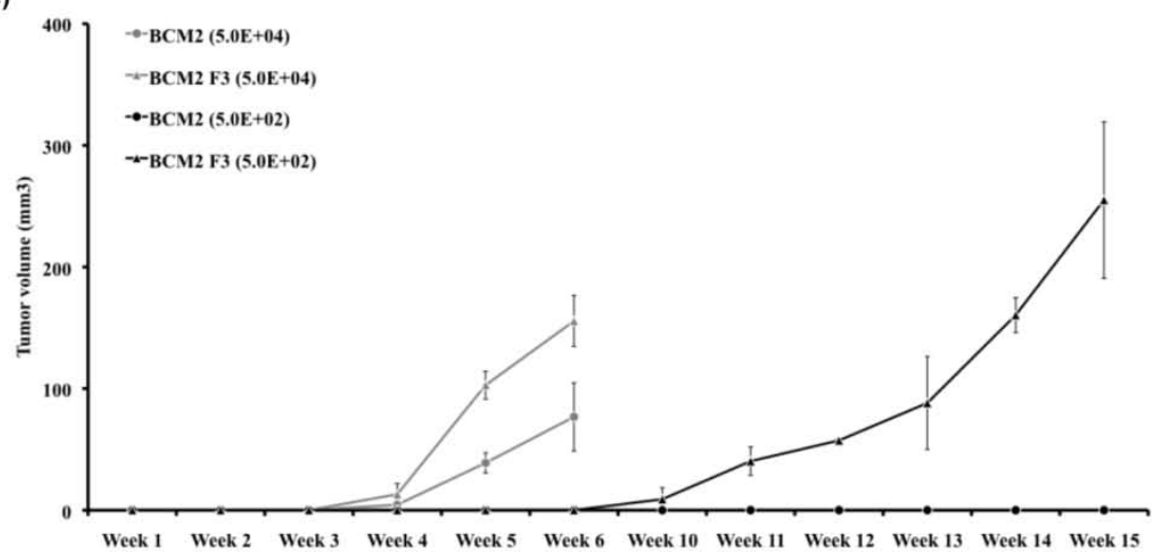

Figure 2 Growth curves of primary tumors generated from the parental cell lines and cycling hypoxia-selected subpopulations. (a) Growth curves of primary tumors in non-obese diabetic/severe combined immunodeficiency disease (NOD/SCID) mice injected with $5 \times 10^{5}$ or $5 \times 10^{4}$ MDA-MB 231 and MDA-MB 231 F3 cells. Tumors were first detected by palpation. Standard errors are derived from duplicate experiments ( $n=6$ per cell number for each experiment). (b) Growth curves of tumors in NOD/SCID mice injected with $5 \times 10^{3}$ or $5 \times 10^{2}$ MDA-MB 231 and MDA-MB 231 F3 cells. Standard errors were derived from duplicate experiments ( $n=5$ per cell number for each experiment), (c) Growth curves of tumors in NOD/SCID mice injected with $5 \times 10^{4}$ or $5 \times 10^{2}$ BCM2 and BCM2 F3 cells. Standard errors were derived from duplicate experiments ( $n=5$ per cell number for each experiment).

population, we also examined the percentage of $\mathrm{CD}_{4} 4^{+} /$ $\mathrm{CD} 24^{-} / \mathrm{ESA}^{+}$and $\mathrm{CD}_{4} 4^{+} / \mathrm{CD} 24^{+} / \mathrm{ESA}^{+}$cell populations in the hypoxia-exposed adherent cells (MDA-MB 231 A3 and BCM2 A3) and found only a slight increase in the percentage of $\mathrm{CD} 44^{+} / \mathrm{CD} 24^{-} / \mathrm{ESA}^{+}$cell population in the hypoxia-exposed adherent cells compared with the parental breast cancer cell lines (1.8-fold increase in MDA-MB 231 A3 cells, Figure 3c; 3.5-fold increase in 
Table 1 Limiting dilution tumor formation of parental, hypoxia-exposed adherent, and cycling hypoxia-selected breast cancer cells in vivo

\begin{tabular}{|c|c|c|c|c|c|}
\hline \multirow[t]{2}{*}{ Cell type } & \multirow[t]{2}{*}{ Days } & \multicolumn{4}{|c|}{ Number injected and tumors formed } \\
\hline & & $5 \times 10^{5}$ & $5 \times 10^{4}$ & $5 \times 10^{3}$ & $5 \times 10^{2}$ \\
\hline MDA-MB 231 (total cell population) & $24-90$ & $5 / 6$ & $2 / 6$ & $0 / 5$ & $0 / 5$ \\
\hline MDA-MB 231 A3 (hypoxia-exposed adherent cells) & 90 & - & - & - & $0 / 5$ \\
\hline MDA-MB 231 F3 (cycling hypoxia-selected subpopulation) & $10-90$ & $6 / 6$ & $6 / 6$ & $5 / 5$ & $4 / 5$ \\
\hline BCM2 (total cell population) & $35-98$ & - & $5 / 5$ & - & $0 / 5$ \\
\hline BCM2 A3 (hypoxia-exposed adherent cells) & 98 & - & - & - & $0 / 5$ \\
\hline BCM2 F3 (cycling hypoxia-selected subpopulation) & $28-98$ & - & $5 / 5$ & - & $4 / 5$ \\
\hline
\end{tabular}

(a)

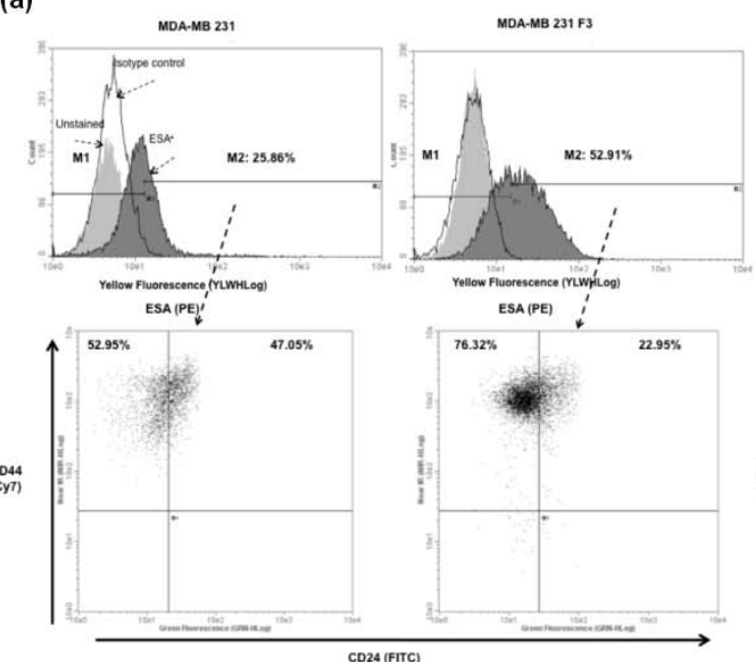

(c) (b)

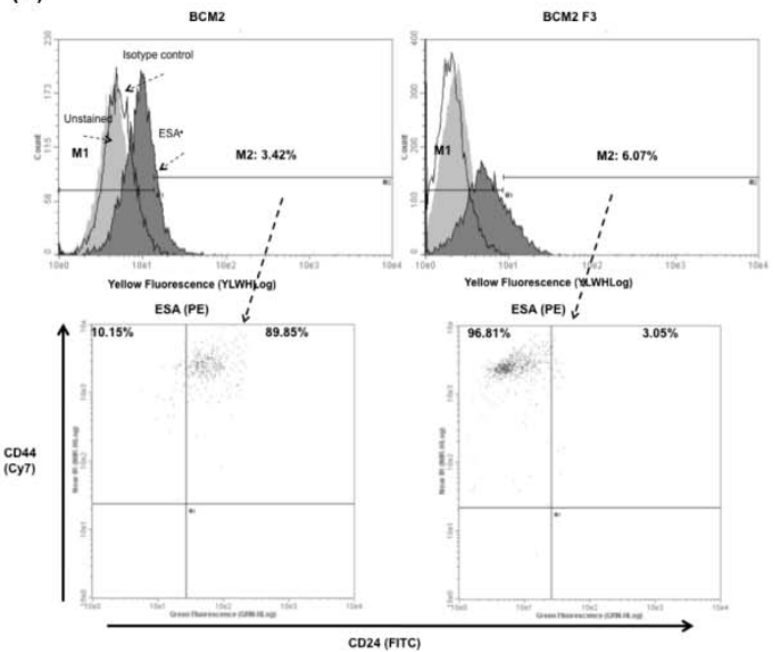

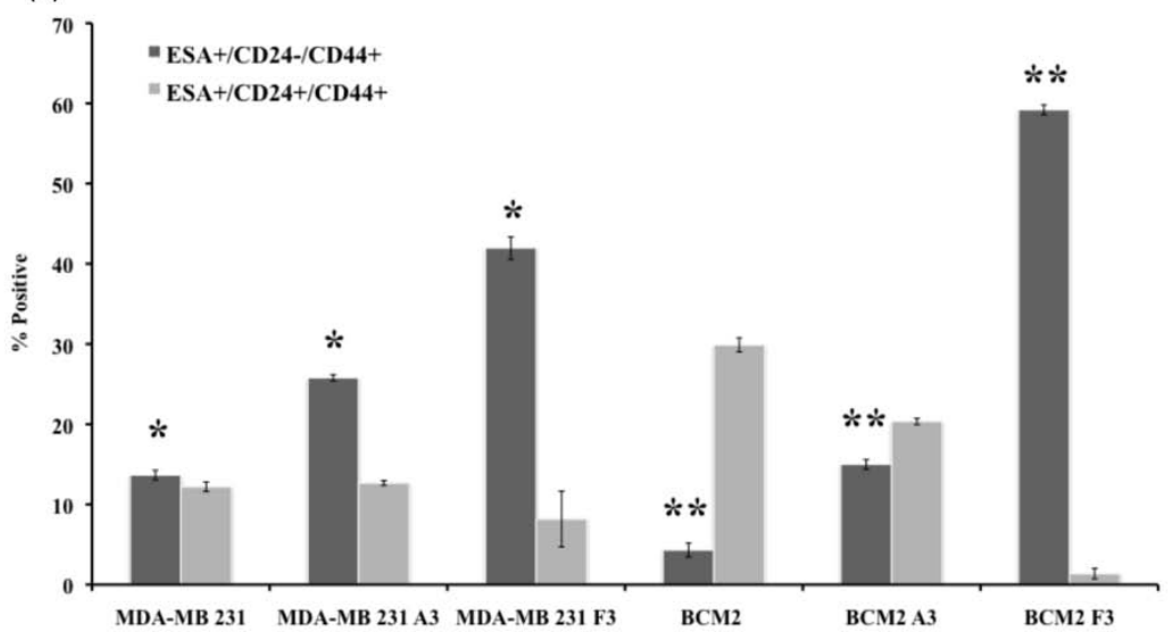

Figure 3 Cell surface expression of ESA, CD44, and CD24. Three-color flow cytometry analysis was performed to detect the CD44 ${ }^{+} / C D 24^{-} /$ $\mathrm{ESA}^{+}$cell population. (a) Top panel: Unstained, isotype control, and ESA-stained cells are shown in the histogram. ESA staining of MDA-MB 231 (total cell population) and MDA-MB 231 F3 (cycling hypoxia-selected subpopulation) cells. M1 marker gates ESA ${ }^{+}$cells, and M2 marker gates the ESA cells. Bottom panel: CD44 and CD24 expression of ESA $A^{+}$cells in each cell line. The percentages of the $\mathrm{CD}_{4} 4^{+} / \mathrm{CD} 24^{-}$and $\mathrm{CD} 44^{+} / \mathrm{CD} 24^{+}$cells within the $\mathrm{ESA}^{+}$cell population are indicated in the Quad plot. (b) The same flow cytometry analysis for BCM2 (total cell population) and BCM2 F3 (cycling hypoxia-selected subpopulation) cells. (c) Quantitative comparison of CD44 $4^{+} / \mathrm{CD}_{2} 4^{-} / \mathrm{ESA}^{+}$cell population and CD44 $/ \mathrm{CD}_{2} 4^{+} / \mathrm{ESA}^{+}$cell population in cycling hypoxia-selected subpopulations (MDA-MB $231 \mathrm{~F} 3$ and BCM2 F3) and their parental breast cancer cell lines. At least three replications were performed to derive the average percentage of each cell population in each cell line and standard deviations. Asterisks indicate statistical significance by two-tail $t$ test $(n=3, P<0.05)$. ESA, epithelial-specific antigen. 
BCM2 A3, Figure 3c). Thus, our data suggest that cyclic exposures of hypoxia and reoxygenation are crucial for the enrichment of stem-like breast cancer cells in this novel non-adherent subpopulation.

It has been shown that tumor-initiating cells or CSCs resemble stem cells in their ability to grow as spheres when cultured under conditions in which they cannot attach to a solid substratum [6,27]. To test whether the increased tumor-initiating capability observed in the cycling hypoxia-selected subpopulations correlates with their ability to grow as tumor spheres in culture, cells from parental cell populations (MDA-MB 231 and BCM2), hypoxia-exposed adherent cells (MDA-MB 231 A3 and BCM2 A3), and cycling hypoxia-selected subpopulations (MDA-MB 231 F3 and BCM2 F3) were plated at low density (500 cells per $0.32 \mathrm{~cm}^{2}$ ) onto ultralow attachment plates in MEM. Images of cells from each well were taken at days $1,3,5$, and 9 to visualize the formation of colonies. After day 5, we noticed that the appearance of compact and asymmetric solid tumor spheres developed in all wells containing MDA-MB 231 F3 and BCM2 F3 cells whereas only small clusters of cells were found in wells containing MDA-MB 231 and BCM2 cells (Figure 4a). By day 9, we observed that some large tumor spheres began to form in the parental cell lines. The time line of tumor-sphere formation was comparable between hypoxia-exposed adherent cells (MDA-MB 231 A3 and BCM2 A3) and their parental cell lines. To determine the CFE of each cell population, tumor spheres of at least $60 \mu \mathrm{m}$ were counted on day 9 after plating. CFE was calculated by dividing the number of tumor spheres formed by the original number of single cells seeded and was expressed as a percentage. Three independent experiments were performed to derive the average CFE and standard deviation per cell line. Although there is around a 2-fold increase in CFE in hypoxia-exposed cells (MDA-MB $231 \mathrm{~A} 3$ and BCM2 A3) compared with the parental cell lines, a larger increase (7- to 8-fold) of CFE was found in the cycling hypoxia-selected subpopulations compared with the parental cell lines (Figure 4b). Therefore, according to our results, the increased tumor-initiating capability of the cycling hypoxia-selected subpopulations is in accordance with the increased ability to grow as spherical colonies in culture.

In addition to showing increased ability to grow as spherical colonies, the stem-like cancer cells were shown to proliferate slower than the bulk cancer cells $[28,29]$. This attribute of stem-like cancer cells has significant clinical implications such as chemoresistance and radioresistance. To determine whether the cycling hypoxia-selected subpopulations cycle slower than the parental and hypoxia-exposed adherent cells, equal numbers of cells from each cell population were plated on day 1 , and an increase in cell numbers over 5 days was used to assess the rate of proliferation. To compare the rate of proliferation under the same condition as the parental and hypoxia-exposed adherent cells, we plated the cycling hypoxia-selected subpopulation as adherent cells (adherent MDA-MB 231 F3 and adherent BCM2 F3) and measured the increase in cell numbers together with the other adherent cell populations. The proliferation of the cycling hypoxia-selected subpopulation as spherical culture was performed separately. While the parental and hypoxia-exposed adherent cells display similar rates of proliferation, the cycling hypoxiaselected subpopulations grow slower as adherent cells and even slower as suspension cultures (Figure 4c). Together, results from established assays for CSC activity show that the cycling hypoxia-selected subpopulation has an increased ability of tumor initiation and tumorsphere formation. More importantly, these findings suggested that our hypoxia/reoxygenation scheme resulted in an enrichment of bona fide breast CSCs without selecting for user-defined markers or targeted genetic manipulation.

The newly isolated cycling hypoxia-selected breast cancer subpopulation is highly metastatic and exhibits increasing epithelial-mesenchymal transition phenotype Aside from their role in tumor initiation, stem-like cancer cells have been hypothesized to contribute directly to cancer metastasis. However, the collective evidence from a few studies examining the metastatic potential of CSCs in vivo suggests that CSC phenotype alone is not enough to determine metastasis. Particularly, a study by Sheridan and colleagues [14] demonstrates that CD44 ${ }^{+} / \mathrm{CD} 24^{-}$stem-like phenotype is not sufficient for homing and proliferation at sites of metastasis, despite a display of increased invasive property in vitro.

Using the human cancer cell xenograft model, we were able to quantify lung metastases 4 weeks after the surgical resection of primary tumors. Images of lungs were taken by a digital camera built into the microscope and were used for quantifying metastases. The National Institutes of Health ImageJ software was used to measure the diameters (width and length) of each visible metastasis on the lung, and total tumor volumes were calculated from each animal (for a description, see Materials and methods). Overall, lungs harvested from mice with primary tumors derived from the cycling hypoxia-selected MDA-MB 231 F3 cells showed significantly more metastases than lungs harvested from mice with parental cell primary tumors (Figure 5a). Mice injected with $5 \times 10^{5}$ MDA-MB $231 \mathrm{~F} 3$ cells showed a 43 -fold greater lung tumor burden, by volume, than mice injected with $5 \times 10^{5}$ parental cells (Figure $5 \mathrm{~b}$ ). Mice injected with $5 \times 10^{4}$ MDA-MB 231 F3 cells had 


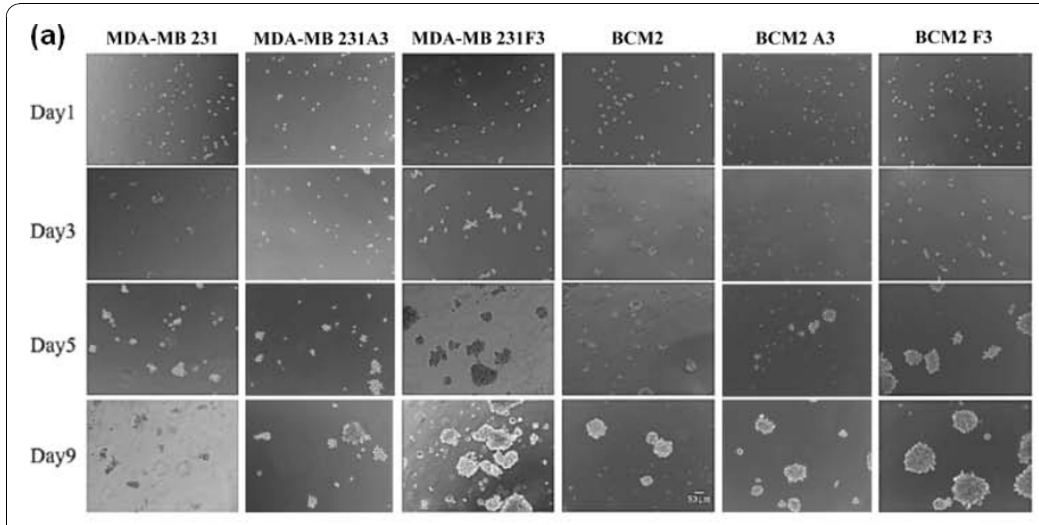

(b)

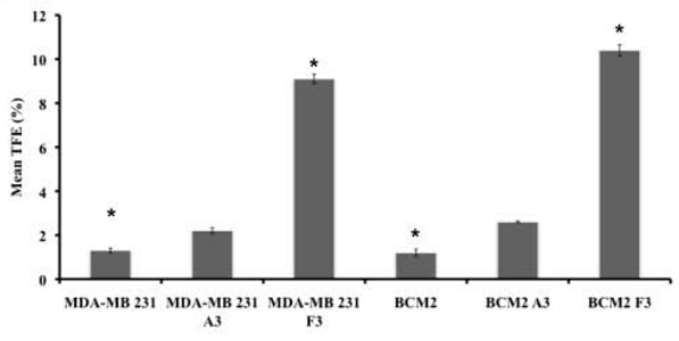

(c)
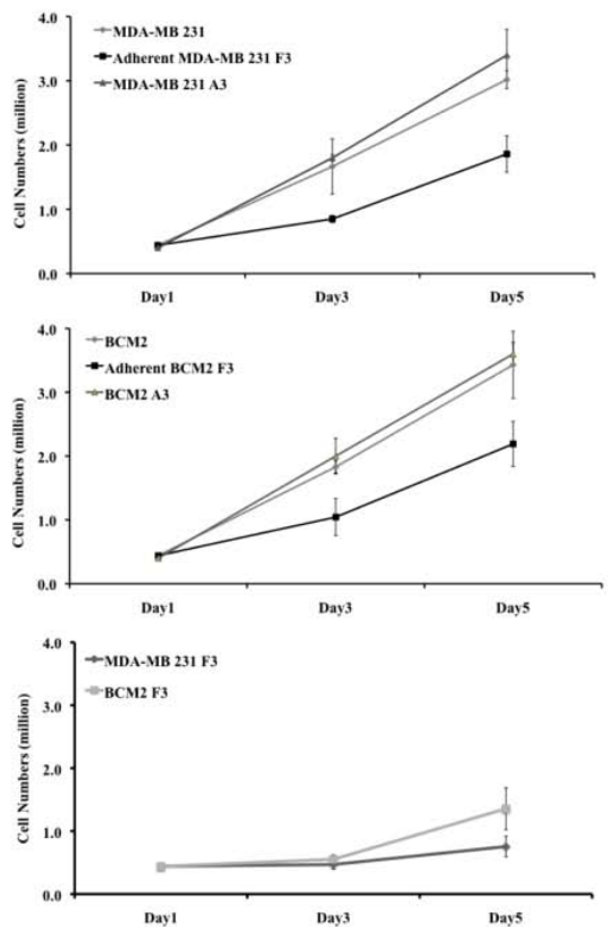

Figure 4 The colony formation and proliferation of the parent cell lines and the cycling hypoxia-selected subpopulations. (a) Images of colony formation assays from 500 cells of MDA-MB 231, MDA-MB 231 A3, MDA-MB F3, BCM2, BCM2 A3, and BCM2 F3 on days 1, 3, 5, and 9. Representative images from three separate experiments are shown. (b) Colony-forming efficiency (CFE) of parental cells, hypoxia-exposed adherent cells (MDA-MB 231 A3 and BCM2 A3), and the cycling hypoxia-selected subpopulations (MDA-MB 231 F3 and BCM2 F3). CFE was determined when tumor spheres were larger than $60 \mu \mathrm{m}$ in diameter on day 9 after plating. CFE was calculated by dividing the number of tumor spheres formed by the original number of single cells seeded and is expressed as a percentage. Three independent experiments were performed to derive the average CFE and standard deviation per cell line. Asterisk indicates statistical significance by two-tail $t$ test $(n=3, P<$ 0.05). (c) Proliferation curves of the parental cells, hypoxia-exposed cells (A3), and the cycling hypoxia-selected subpopulations grown as adherent cultures (top two plots) or as spherical cultures (the third plot). Total viable cells from each well at days 3 and 5 were counted by the ViaCount assay using the Guava Flow Cytometer. Average cell numbers and standard deviations at each time point were calculated from three independent experiments.

76-fold greater lung tumor burden than mice injected with $5 \times 10^{4}$ parental cells (Figure 5b). Remarkably, mice injected with 100 -fold and 1,000-fold less MDAMB 231 F3 cells showed a less than 10-fold reduction in metastatic tumor burden, whereas this number of parental cells failed to form substantial metastases, indicating that the cycling hypoxia-selected subpopulation is highly metastatic in vivo.

Growing evidence demonstrates that many genes and proteins known to play essential roles during embryonic development are mutated or aberrantly expressed in cancerous cells. One of the most widely studied regulatory programs that controls normal developmental processes and contributes to tumor progression is the EMT [30,31]. Recently, it was shown that inducing EMT could generate mammary epithelial stem-like cells [15]. Furthermore, stem-like cancer cells exhibit EMT characteristics such as the loss of E-cadherin, increased expression of fibronectin and vimentin, and increased expression of mesenchymal transcription factors (Snail, Twist, and Slug) [32-34]. Therefore, we speculated that EMT plays a role in the increased tumorigenicity and metastatic potential of the cycling hypoxia-selected subpopulation. Indeed, we found specific molecular changes consistent with increased EMT in the cycling hypoxiaselected F3 subpopulations. MDA-MB 231 F3 and BCM2 F3 cells had an increased percentage of Ecadherin-negative cell population ( $8 \%$ to $10 \%$ increase) compared with the parental cell lines (Figure 6a; Figure S1 in Additional file 1). Within the E-cadherin-negative cell population, there was also an increased percentage of $\mathrm{CD} 44^{+} / \mathrm{CD} 24^{-}$cell population in the F3 subpopulations (27\% increase in MDA-MB $231 \mathrm{~F} 3$ and 35\% increase in BCM2 F3) compared with the parental cell lines (Figure 6b). Since the loss of E-cadherin is a hallmark of increased EMT, the cycling hypoxia-selected F3 subpopulations appear to be enriched with stem-like and EMT cells. 


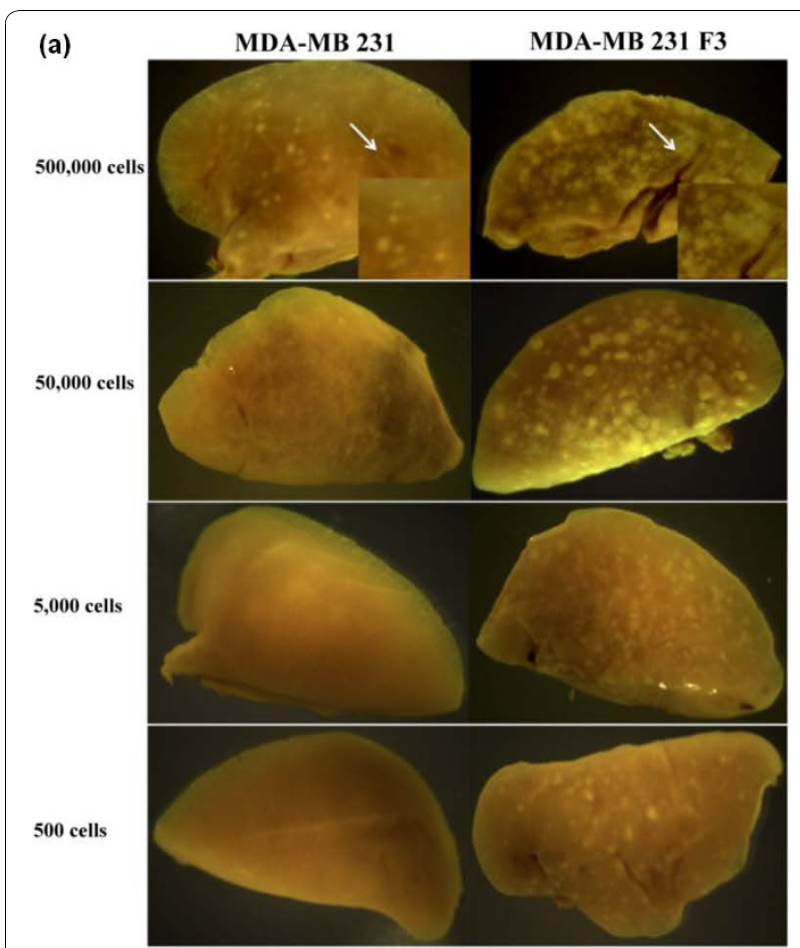

(b)

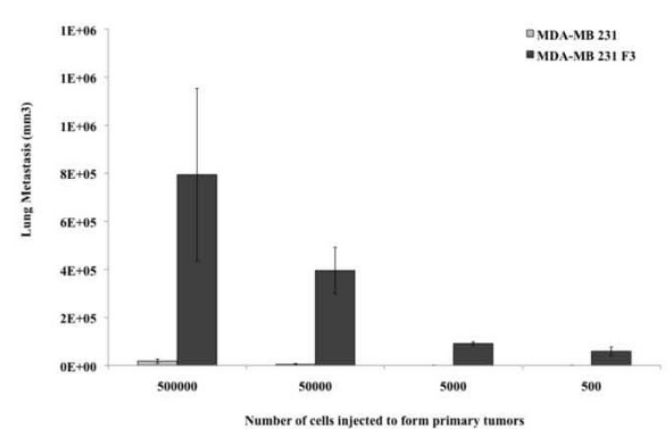

Figure $\mathbf{5}$ Lung metastases from the tumor-initiating assays (a) Representative images of lungs from tumor-bearing non-obese diabetic/severe combined immunodeficiency disease (NOD/SCID) mice are shown $(n=6)$. A higher magnification of lung metastases derived from orthotopic injection of $5 \times 10^{5}$ MDA-MB 231 or MDAMB 231 F3 cells is shown in the lower right corner. (b) Quantitative analysis of the metastatic tumor burden in the lung. Images of lungs were taken using a digital microscope camera. Images were imported into the National Institutes of Health ImageJ software for quantitative analysis. The sum of metastatic tumor volume was first calculated from four lobes of lungs per animal (see Materials and methods), and the lung metastasis per group is presented as tumor volume (cubic millimeters). The number of animals used per group is listed in Table 1.

Several transcription factors have been implicated in the transcriptional repression of E-cadherin. One of the first discovered and most important transcriptional repressors of E-cadherin is Snail [35]. Expression of Snail represses expression of E-cadherin and induces EMT in different cell types, including breast cancer cells
$[36,37]$. Therefore, we speculated that molecular machinery found to promote EMT might also be upregulated in the cycling hypoxia-selected subpopulation. Consistent with a decrease in E-cadherin expression, MDA-MB 231 F3 and BCM2 F3 cells had increased nuclear expression of Snail and cytoplasmic expression of a mesenchymal marker vimentin (Figure 6c). Quantitative analysis of Snail and vimentin protein expression by Western blotting revealed a 3 - to 4 -fold increase in nuclear Snail expression and an 8- to 9-fold increase in vimentin expression in the MDA-MB 231 F3 and BCM2 F3 cells compared with the parental and hypoxiaexposed A3 subpopulations (Figure 6c). Furthermore, the cycling hypoxia-selected F3 subpopulations had increased mRNA levels of three mesenchymal transcription factors - Snail (7- to 10-fold), Slug (2- to 3-fold), and Twist (2- to 4-fold) - as measured by qRT-PCR (Figure 6d).

In addition to EMT-regulatory factors, regulatory molecules such as miRNAs can play a role in promoting stemlike and EMT phenotypes in cancer cells. Using a qRTPCR-based method, we found dramatic decreases of epithelial miRNAs (miR200c and miR205) in the F3 subpopulations compared with the parental breast cancer cell lines (Figure 6e). It has been reported that human breast CSCs and normal human mammary stem/progenitor cells showed decreased expression of miR200c and other miR200 members and that restoring miR200c in breast CSCs inhibits their ability to expand clonally and form tumors in vivo [38]. Hence, downregulation of miR200c and miR205 in the cycling hypoxia-selected subpopulation corroborates with the stem-like phenotype exhibited in this subpopulation. In addition to miRNA200c and miR205, the cycling hypoxia-selected subpopulation showed decreased miR215 expression (Figure 6e). miR215 suppresses EMT by suppressing the mesenchymal transcription factor ZEB2 and increasing the E-cadherin level [39]. Therefore, downregulation of miR-215 could promote EMT phenotype in downregulation of E-cadherin and promote EMT phenotype in the cycling hypoxiaselected subpopulation. Together, our results reinforce the idea that EMT and stem cell factors work cooperatively in highly tumorigenic cancer subpopulations and raise interesting questions about their contribution to the increased metastatic capability observed in the cycling hypoxiaselected subpopulation.

\section{Discussion}

Some studies have shown that external influences, such as hypoxia, can drive a 'reversible' phenotype that can enhance stem-like properties of cells to ensure survival of the tumor. Also, hypoxia-inducible factors have been shown to play a role in CSC self-renewal and tumor growth. It was reported, for example, that CSC state 
(a)
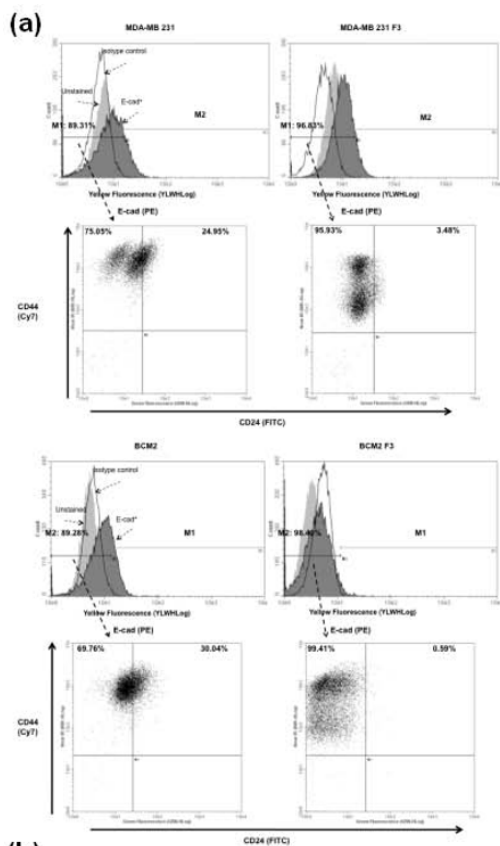

(b)

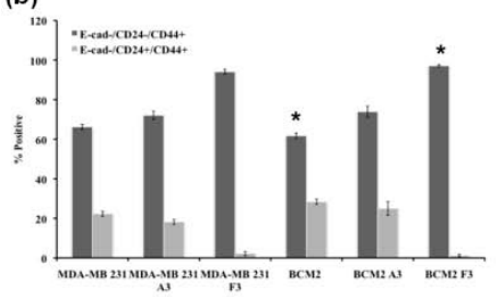

(c)
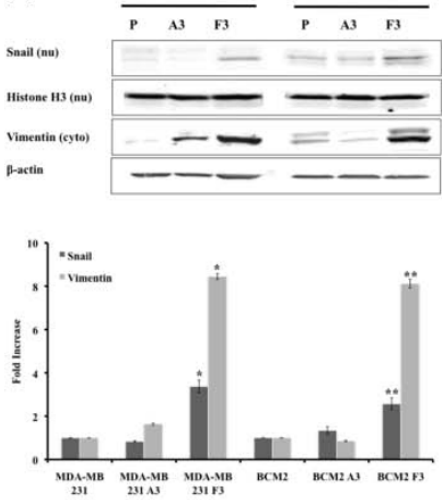

(d)

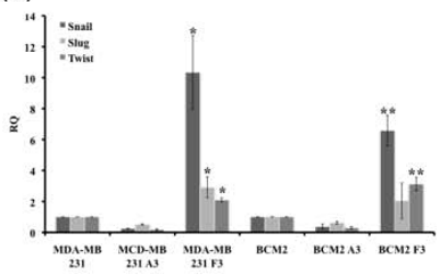

(e)
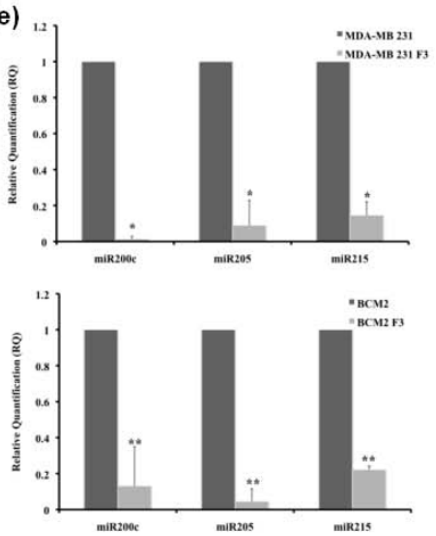

Figure 6 Expression of epithelial-mesenchymal transition (EMT)-associated markers in the total cell population and the cycling hypoxiaselected subpopulation. (a) Three-color fluorescence-activated cell sorting (FACS) analysis was performed to detect CD44CD24 expression profile on the E-cadherin-negative cell population. Unstained, isotype control, and E-cadherin (E-cad)-stained cells are shown in the histogram. ESA staining of MDA-MB 231 (total cell population) and MDA-MB 231 F3 (cycling hypoxia-selected subpopulation) cells is shown. M1 marker gates Ecadherin-positive cells, and M2 marker gates the E-cadherin-negative cells. Bottom panel: CD44 and CD24 expression of E-cadherin-negative cells in each cell line. The percentages of the $\mathrm{CD} 44^{+} / \mathrm{CD} 24^{-}$and $\mathrm{CD} 44^{+} / \mathrm{CD} 24^{+}$cells are indicated in the Quad plot. (b) Quantitative comparison of E-cad $/$ $\mathrm{CD}_{4} 4^{+} / \mathrm{CD} 24^{-}$cell population and E-cad $/ \mathrm{CD}_{4} 4^{+} / \mathrm{CD} 24^{+}$cell population in cycling hypoxia-selected subpopulations (MDA-MB 231 F3 and BCM2 F3) and their parental breast cancer cell lines. At least three replications were performed to derive the average percentage of each cell population in each cell line and standard deviations among the replicates. (c) Expression of EMT-associated proteins in the parental cells (P), hypoxia-exposed adherent cells (A3), and the cycling hypoxia-selected subpopulations (F3). Lysates from these two cell populations were fractionated on the basis of the subcellular localization using the ProteoExtract Kit, and $40 \mu \mathrm{g}$ of proteins was loaded for Western blotting. Beta-actin is used as the loading control for the cytoplasmic fraction, and histone $\mathrm{H} 3$ is used as the loading control for the nuclear fraction. Western blot images $(n=3)$ are quantified by National Institutes of Health ImageJ software and presented as fold increase in A3 and F3 cells compared with the parental cell lines. (d) mRNA regulation of EMT transcription factors in the parental, A3, and F3 cells. Quantitative reverse transcription-polymerase chain reaction (qRTPCR) analyses were performed using specific primers to measure the mRNA expression of human Snail, Slug, and Twist genes in these three cell populations. At least three replications $(n=3)$ were performed to derive the average percentage of each cell population in each cell line and standard deviations among the replicates. (e) Expression of EMT-suppressing microRNAs (miRNAs) in the parental, A3, and F3 cells. qRT-PCR analyses were performed using specific primers to measure the expression of miR200c and miR205. At least three replications $(n=3)$ were performed to derive the average percentage of each cell population in each cell line and standard deviations among the replicates. Asterisks indicate statistical significance by two-tail $t$ test $(P<0.05)$ for all quantitative results. ESA, epithelial-specific antigen.

could be maintained by overexpressing hypoxia-inducible transcription factor (HIF2 $\alpha$ ) in glioma cell lines [40]. However, only few studies showed or discussed the possibility of establishing irreversible phenotypes through cycling hypoxic exposure without genetic manipulation $[41,42]$. In our study, we found that exposing metastatic breast cancer cell lines to hypoxia and reoxygenation cycles induces a unique subpopulation that is highly metastatic and exhibits stem-like and EMT phenotypes. Our results led us to speculate that there might be a metastatic subpopulation within stem-like cancer cells since other studies have shown that CSC phenotype alone may exhibit invasive property in vitro but is inadequate to determine or predict in vivo metastasis. 
Furthermore, we found that the stem-like and EMT phenotypes observed in the cycling hypoxia-selected subpopulation are not reversible, because we obtained the same molecular profile from this subpopulation by culturing them as spherical cultures for several months in normal oxygen content and culturing them as adherent cells (Figure S2 in Additional file 2).

Nevertheless, we believe hypoxia is only a partial driving force for the metastatic CSC enrichment. Our study showed that reoxygenation might also play a role in selecting stem-like breast cancer cells. The occurrence of reoxygenation following hypoxic exposures of various degrees is inherent in the dynamic nature of the tumor vasculature $[43,44]$. Fluctuating oxygen tensions in tumors could lead to reoxygenation-induced DNA damage and potentially increased genomic instability [45]. A hypoxia-dependent decrease in DNA repair could lead to the accumulation of unrepaired lesions in tumors and contribute to tumor progression [46]. A recent study by Pires and colleagues [23] showed that cells that are exposed acutely to hypoxia are able to restart replication regardless of the presence of active checkpoint response and reoxygenation-induced DNA damage. However, chronic exposure of cells to hypoxia induces disassembly of the replisome, preventing replication restart after reoxygenation [23]. In our study, we found that the emergence of a small non-adherent subpopulation (approximately 1\%) survived after the first hypoxia/reoxygenation cycle and speculate that cyclic exposures of hypoxia and reoxygenation may select for the stem-like subpopulation with the ability to overcome replication arrest whereas the majority of non-adherent cells cannot. Also, as shown in our study, the surviving cycling hypoxia-selected subpopulation acquires additional molecular advantages after exposure to several cycles of hypoxia/reoxygenation.

Phillips and colleagues [47] reported that the non-adherent population of monolayer cultures of breast cancer cells has the ability to initiate mammosphere formation after irradiation. Other groups have also reported that exposing cancer cells to environmental factors such as serum deprivation or hypoxia alone can increase the stem-like phenotype or the number of stem-like cancer cells $[40,48,49]$. Collectively, our results support the idea that a stem-like subpopulation in the tumor could expand selectively in response to changes in the microenvironment. However, it is unclear whether the same stem-like subpopulation or a different one is generated by various conditions. To compare the non-adherent population described by Phillips and colleagues [47] and our F3 non-adherent subpopulation, we studied the expression level of Snail, an EMT transcription factor, in these two cell populations. Our results showed that the expression of Snail is robustly increased in cycling hypoxia-selected F3 cells compared with the non-nutrient-deprived floating cell population and the parental cell lines (Figure S2 in Additional file 2). Although our data indicate that these two cell populations are not the same, it is possible that this small viable floating cell population expands and gives rise to the F3 cell population after exposing cancer cells to cycling hypoxia and reoxygenation. We are currently exploring this possibility and hope to elucidate the mechanism and relevance of the cycling hypoxia-selected cell population in breast cancer progression.

\section{Conclusions}

Although many studies have suggested the potential of CSCs as the seeds for distal metastasis, few studies have directly tested the metastatic capability of putative CSCs in vivo. Collective evidence from a few studies that directly tested the in vivo metastasis using sorted CSCs suggests that the CSC phenotype alone may exhibit invasive property in vitro but is not sufficient to determine or predict in vivo metastasis. Here, we show that a nonadherent, stem-like, and metastatic CSC-enriched subpopulation could be isolated by exposing human metastatic breast cancer cell lines to cycles of chronic hypoxia followed by reoxygenation. Since very few studies have demonstrated the formation of macro-metastasis from low numbers of sorted CSCs and currently proposed CSC markers might not be sufficient to identify all stem cell populations [13], we believe that our study presents a promising approach to isolate stem-like and metastatic breast CSCs as opposed to the cell-sorting strategy based on putative stem cell surface markers. Also, it will be of great interest to investigate the possibility that repetitive cycles of hypoxia/reoxygenation lead to the selective expansion of a pre-existing metastatic CSC subpopulation. Our results demonstrated the possibility of isolating highly metastatic breast CSCs using the hypoxia/reoxygenation regimen we established. With the recent success of identifying selective inhibitors targeting CSCs, we believe that the newly isolated cycling hypoxia-selected subpopulation may present a new opportunity for chemical screening and discovery of compounds with selective toxicity for metastatic breast CSCs.

\section{Additional material}

Additional file 1: Figure S1. Gating parameters of ESA ${ }^{+} / \mathrm{CD}^{2} 4^{-} / \mathrm{CD} 44^{+}$ $\mathrm{ESA}^{+} / \mathrm{CD} 24^{+} / \mathrm{CD} 44^{+}, \mathrm{E}-\mathrm{Cad}^{+} / \mathrm{CD} 24^{-} / \mathrm{CD} 44^{+}$, and $\mathrm{E}-\mathrm{Cad}^{+} / \mathrm{CD} 24^{+} / \mathrm{CD} 44^{+}$cells using the Guava EasyCyte Flow Cytometer.

Additional file 2: Figure S2. mRNA regulation of Snail in the parental, non-nutrient deprived (Flo), cycling hypoxia-selected cells grown in suspension culture (F3), and cycling hypoxia-selected cells grown in monolayer culture (F3 AD). Quantitative qRT-PCR analyses were performed using specific primers to measure the mRNA expression of the human Snail gene. Minimum three replications $(n=3)$ were performed to derive the average percentage of each cell population in each cell line and standard deviations among the replicates. 


\section{Abbreviations}

CFE: colony-forming efficiency; CSC: cancer stem cell; EDTA:

ethylenediaminetetraacetic acid; EMT: epithelial-mesenchymal transition; ESA: epithelial-specific antigen; MEM: minimum essential medium; MIRNA: microRNA; NOD/SCID: non-obese diabetic/severe combined immunodeficiency disease; PBS: phosphate-buffered saline; RQ: relative quantification; RT-PCR: reverse transcription-polymerase chain reaction; QRTPCR: quantitative reverse transcription-polymerase chain reaction.

\section{Acknowledgements}

The authors would like to thank Howard Crawford for valuable comments. This work was supported by grants to EC from the Susan Komen Foundation and the Mary Anita Conroy Memorial Breast Cancer Fund from the Manhasset Women's Coalition Against Breast Cancer. BS and JJ are supported by the Stony Brook University Translational Research Laboratory Start-up fund and MH075020.

\section{Author details}

'Department of Pharmacological Sciences, Stony Brook University, BST-125, Stony Brook, NY 11794, USA. ${ }^{2}$ Department of Pathology, Stony Brook University Medical Center, Stony Brook, NY 11794, USA.

\section{Authors' contributions}

EL helped to carry out the optimization of hypoxia/reoxygenation protocol, carried out the flow cytometry experiments and animal experiments, and prepared the manuscript. SC and MS helped to carry out the optimization of hypoxia/reoxygenation protocol. SN designed and performed the Western blot analysis and helped to design and perform tumor-sphere formation assays. CP helped to design and perform tumor-sphere formation assays. SP performed the real-time polymerase chain reaction analysis. XC performed the quantification of lung metastases. BS and $\mathrm{J} J$ helped to perform and provide results for the miRNA analysis. EC helped to perform animal experiments and prepare the manuscript. All authors read and approved the final manuscript.

\section{Competing interests}

The authors declare that they have no competing interests.

Received: 20 April 2010 Revised: 12 August 2010

Accepted: 10 November 2010 Published: 10 November 2010

\section{References}

1. Al-Hajj M, Wicha MS, Benito-Hernandez A, Morrison SJ, Clarke MF: Prospective identification of tumorigenic breast cancer cells. Proc Natl Acad Sci USA 2003, 100:3983-3988.

2. Horst D, Scheel SK, Liebmann S, Neumann J, Maatz S, Kirchner T, Jung A: The cancer stem cell marker CD133 has high prognostic impact but unknown functional relevance for the metastasis of human colon cancer. J Pathol 2009, 219:427-434.

3. Ghosh N, Matsui W: Cancer stem cells in multiple myeloma. Cancer Lett 2009, 277:1-7.

4. Bednar F, Simeone DM: Pancreatic cancer stem cells and relevance to cancer treatments. J Cell Biochem 2009, 107:40-45.

5. Wright MH, Calcagno AM, Salcido CD, Carlson MD, Ambudkar SV, Varticovski L: Brca1 breast tumors contain distinct CD44+/CD24- and CD133+ cells with cancer stem cell characteristics. Breast Cancer Res 2008, 10:R10.

6. Singh SK, Clarke ID, Terasaki M, Bonn VE, Hawkins C, Squire J, Dirks PB: Identification of a cancer stem cell in human brain tumors. Cancer Res 2003, 63:5821-5828.

7. Lang SH, Frame FM, Collins AT: Prostate cancer stem cells. J Pathol 2009, 217:299-306.

8. O'Brien CA, Kreso A, Dick JE: Cancer stem cells in solid tumors: an overview. Semin Radiat Oncol 2009, 19:71-77.

9. Marotta LL, Polyak K: Cancer stem cells: a model in the making. Curr Opin Genet Dev 2009, 19:44-50.

10. Waterworth A: Introducing the concept of breast cancer stem cells. Breast Cancer Res 2004, 6:53-54

11. Reya T, Morrison SJ, Clarke MF, Weissman IL: Stem cells, cancer, and cancer stem cells. Nature 2001، 414:105-111.
12. Al-Hajj M, Clarke MF: Self-renewal and solid tumor stem cells. Oncogene 2004, 23:7274-7282.

13. Stuelten CH, Mertins SD, Busch II, Gowens M, Scudiero DA, Burkett MW, Hite KM, Alley M, Hollingshead M, Shoemaker RH, Niederhuber JE: Complex display of putative tumor stem cell markers in the NCl60 tumor cell line panel. Stem Cells 2010, 28:649-660.

14. Sheridan C, Kishimoto $\mathrm{H}$, Fuchs RK, Mehrotra S, Bhat-Nakshatri P, Turner $\mathrm{CH}$, Goulet R Jr, Badve S, Nakshatri H: CD44+/CD24- breast cancer cells exhibit enhanced invasive properties: an early step necessary for metastasis. Breast Cancer Res 2006, 8:R59.

15. Mani SA, Guo W, Liao MJ, Eaton EN, Ayyanan A, Zhou AY, Brooks M, Reinhard F, Zhang CC, Shipitsin M, Campbell LL, Polyak K, Brisken C, Yang J, Weinberg RA: The epithelial-mesenchymal transition generates cells with properties of stem cells. Cell 2008, 133:704-715.

16. Abraham BK, Fritz $P$, McClellan M, Hauptvogel P, Athelogou M, Brauch H: Prevalence of CD44+/CD24-/low cells in breast cancer may not be associated with clinical outcome but may favor distant metastasis. Clin Cancer Res 2005, 11:1154-1159.

17. Hermann PC, Huber SL, Herrler T, Aicher A, Ellwart JW, Guba M, Bruns CJ, Heeschen C: Distinct populations of cancer stem cells determine tumor growth and metastatic activity in human pancreatic cancer. Cell Stem Cell 2007, 1:313-323.

18. Graeber TG, Osmanian C, Jacks T, Housman DE, Koch CJ, Lowe SW, Giaccia AJ: Hypoxia-mediated selection of cells with diminished apoptotic potential in solid tumours. Nature 1996, 379:88-91.

19. Brown NS, Bicknell R: Hypoxia and oxidative stress in breast cancer. Oxidative stress: its effects on the growth, metastatic potential and response to therapy of breast cancer. Breast Cancer Res 2001, 3:323-327.

20. Wouters BG, van den Beucken T, Magagnin MG, Lambin P, Koumenis C: Targeting hypoxia tolerance in cancer. Drug Resist Updat 2004, 7:25-40.

21. Huang LE, Bindra RS, Glazer PM, Harris AL: Hypoxia-induced genetic instability-a calculated mechanism underlying tumor progression. $J \mathrm{Mol}$ Med 2007, 85:139-148.

22. Postovit LM, Abbott DE, Payne SL, Wheaton WW, Margaryan NV, Sullivan R, Jansen MK, Csiszar K, Hendrix MJ, Kirschmann DA: Hypoxia/reoxygenation: a dynamic regulator of lysyl oxidase-facilitated breast cancer migration. J Cell Biochem 2008, 103:1369-1378.

23. Pires IM, Bencokova Z, Milani M, Folkes LK, Li JL, Stratford MR, Harris AL, Hammond EM: Effects of acute versus chronic hypoxia on DNA damage responses and genomic instability. Cancer Res 70:925-935.

24. Chen El, Hewel J, Krueger JS, Tiraby C, Weber MR, Kralli A, Becker K, Yates JR, Felding-Habermann B: Adaptation of energy metabolism in breast cancer brain metastases. Cancer Res 2007, 67:1472-1486.

25. Cheshier SH, Kalani MY, Lim M, Ailles L, Huhn SL, Weissman IL: A neurosurgeon's quide to stem cells, cancer stem cells, and brain tumor stem cells. Neurosurgery 2009, 65:237-249, discussion 249-250; quiz N236.

26. Dontu G, Al-Hajj M, Abdallah WM, Clarke MF, Wicha MS: Stem cells in normal breast development and breast cancer. Cell Prolif 2003, 36(Suppl 1):59-72.

27. Ponti D, Costa A, Zaffaroni N, Pratesi G, Petrangolini G, Coradini D, Pilotti S, Pierotti MA, Daidone MG: Isolation and in vitro propagation of tumorigenic breast cancer cells with stem/progenitor cell properties. Cancer Res 2005, 65:5506-5511.

28. Fillmore $C M$, Kuperwasser C: Human breast cancer cell lines contain stemlike cells that self-renew, give rise to phenotypically diverse progeny and survive chemotherapy. Breast Cancer Res 2008, 10:R25.

29. Gupta PB, Onder TT, Jiang G, Tao K, Kuperwasser C, Weinberg RA, Lander ES: Identification of selective inhibitors of cancer stem cells by high-throughput screening. Cell 2009, 138:645-659.

30. Kalluri R: EMT: when epithelial cells decide to become mesenchymal-like cells. J Clin Invest 2009, 119:1417-1419.

31. Yilmaz M, Christofori G: EMT, the cytoskeleton, and cancer cell invasion. Cancer Metastasis Rev 2009, 28:15-33.

32. Kang $Y$, Massague J: Epithelial-mesenchymal transitions: twist in development and metastasis. Cell 2004, 118:277-279.

33. Javle MM, Gibbs JF, Iwata KK, Pak Y, Rutledge P, Yu J, Black JD, Tan D, Khoury T: Epithelial-mesenchymal transition (EMT) and activated extracellular signal-regulated kinase ( $p$-Erk) in surgically resected pancreatic cancer. Ann Surg Oncol 2007, 14:3527-3533.

34. Cano A, Perez-Moreno MA, Rodrigo I, Locascio A, Blanco MJ, del Barrio MG, Portillo F, Nieto MA: The transcription factor snail controls epithelial- 
mesenchymal transitions by repressing E-cadherin expression. Nat Cell Biol 2000, 2:76-83.

35. Nieto MA: The snail superfamily of zinc-finger transcription factors. Nat Rev Mol Cell Biol 2002, 3:155-166.

36. Bolos V, Peinado H, Perez-Moreno MA, Fraga MF, Esteller M, Cano A: The transcription factor Slug represses E-cadherin expression and induces epithelial to mesenchymal transitions: a comparison with Snail and E47 repressors. J Cell Sci 2003, 116:499-511.

37. Elloul $S$, Elstrand MB, Nesland JM, Trope CG, Kvalheim G, Goldberg I, Reich R, Davidson B: Snail, Slug, and Smad-interacting protein 1 as novel parameters of disease aggressiveness in metastatic ovarian and breast carcinoma. Cancer 2005, 103:1631-1643.

38. Shimono Y, Zabala M, Cho RW, Lobo N, Dalerba P, Qian D, Diehn M, Liu H, Panula SP, Chiao E, Dirbas FM, Somlo G, Pera RA, Lao K, Clarke MF: Downregulation of miRNA-200c links breast cancer stem cells with normal stem cells. Cell 2009, 138:592-603.

39. Wang B, Herman-Edelstein M, Koh P, Burns W, Jandeleit-Dahm K, Watson A, Saleem M, Goodall GJ, Twigg SM, Cooper ME, Kantharidis P: E-cadherin expression is regulated by miR-192/215 by a mechanism that is independent of the profibrotic effects of TGF $\{$ beta\}. Diabetes 2010, 59:1794-1802

40. Heddleston JM, Li Z, McLendon RE, Hjelmeland AB, Rich JN: The hypoxic microenvironment maintains glioblastoma stem cells and promotes reprogramming towards a cancer stem cell phenotype. Cell Cycle 2009, 8:3274-3284.

41. van den Beucken T, Koritzinsky M, Wouters BG: Translational control of gene expression during hypoxia. Cancer Biol Ther 2006, 5:749-755.

42. Koritzinsky M, Magagnin MG, van den Beucken T, Seigneuric R, Savelkouls K, Dostie J, Pyronnet S, Kaufman RJ, Weppler SA, Voncken JW, Lambin P, Koumenis C, Sonenberg N, Wouters BG: Gene expression during acute and prolonged hypoxia is regulated by distinct mechanisms of translational control. Embo J 2006, 25:1114-1125.

43. Brown JM, Wilson WR: Exploiting tumour hypoxia in cancer treatment Nat Rev Cancer 2004, 4:437-447.

44. Cardenas-Navia LI, Mace D, Richardson RA, Wilson DF, Shan S, Dewhirst MW: The pervasive presence of fluctuating oxygenation in tumors. Cancer Res 2008, 68:5812-5819.

45. Aguilera A, Gomez-Gonzalez B: Genome instability: a mechanistic view of its causes and consequences. Nat Rev Genet 2008, 9:204-217.

46. Bindra RS, Crosby ME, Glazer PM: Regulation of DNA repair in hypoxic cancer cells. Cancer Metastasis Rev 2007, 26:249-260.

47. Phillips TM, McBride WH, Pajonk F: The response of CD24(-/low)/CD44+ breast cancer-initiating cells to radiation. J Natl Cancer Inst 2006, 98:1777-1785

48. Tavaluc RT, Hart LS, Dicker DT, El-Deiry WS: Effects of low confluency, serum starvation and hypoxia on the side population of cancer cell lines. Cell cycle 2007, 6:2554-2562

49. Blazek ER, Foutch JL, Maki G: Daoy medulloblastoma cells that express CD133 are radioresistant relative to CD133- cells, and the CD133+ sector is enlarged by hypoxia. Int J Radiat Oncol Biol Phys 2007, 67:1-5.

doi:10.1186/bcr2773

Cite this article as: Louie et al:: Identification of a stem-like cell population by exposing metastatic breast cancer cell lines to repetitive cycles of hypoxia and reoxygenation. Breast Cancer Research 2010 12:R94.

\section{Submit your next manuscript to BioMed Central and take full advantage of:}

- Convenient online submission

- Thorough peer review

- No space constraints or color figure charges

- Immediate publication on acceptance

- Inclusion in PubMed, CAS, Scopus and Google Scholar

- Research which is freely available for redistribution

Submit your manuscript at www.biomedcentral.com/submit
Biomed Central 